\title{
Influence of Stocking Density with Different Light System on the Growth Performance and Behavior in Broiler Chickens
}

\author{
Chun Ik Lim¹, Md Masud Rana ${ }^{1}$, Il Bok Choi ${ }^{1}$ and Kyeong Seon Ryu ${ }^{2+}$ \\ ${ }^{1}$ Student, Department of Animal Science, Chonbuk National University, Jeonju 54896, Republic of Korea \\ ${ }^{2}$ Professor, Department of Animal Science, Chonbuk National University, Jeonju 54896, Republic of Korea
}

\begin{abstract}
This study evaluated the effects of stocking density on performance and behavioral activities of 35-day-old broilers in relation to incandescent white bulb (IB) light and LED yellow and white light. A total of 1,650 day-old chicks were weighed and randomly allocated into six treatment groups in a $2 \times 3$ factorial arrangement based on stocking density (14 birds $\mathrm{m}^{-2}$ and 22 birds $\mathrm{m}^{-2}$ ) and color of lights (IB; monochromatic LED yellow and white light) with five replicates for each treatment. The results showed that final body weight, weight gain and feed conversion of broilers were improved at a stocking density of 14 birds $\mathrm{m}^{-2}$ with exposure to LED lights. Similarly, broilers spent more time exhibiting inactive

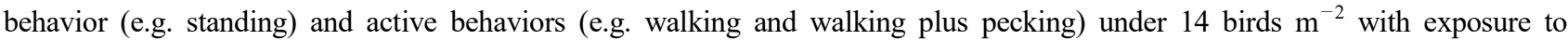

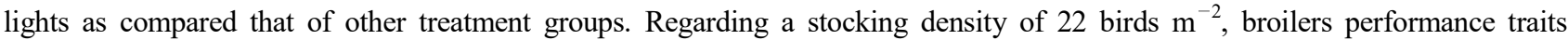
were negatively affected and also activities were less. The performance of broilers was not significantly altered for the main factor of different lights but broilers were less inactive (e.g less time spent sitting plus standing) and more time spent active

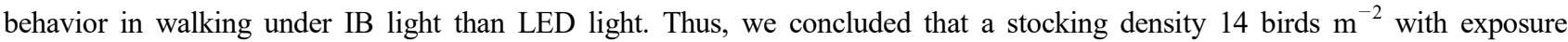
to LED light significantly improved broiler performance and behavioral activity and these conditions could therefore improve the overall welfare of farmed chickens.
\end{abstract}

(Key words: stocking density, light, performance, behavior, broiler)

\section{INTRODUCTION}

In order to achieve the genetic potentiality, broilers like other live species must be reared under optimal management and environmental conditions, if any major deviations occur, in which may impair their performance, cause immune suppression, change their physiological responses and increasing their susceptibility to disease. One of the key subjects for the economical result of broiler production is stocking density, in general, stocking density can be expressed by two ways, as the number of birds or the total live weight of birds $(\mathrm{kg})$ in a house at the same time per unit space. The significance of stocking density on the performance parameters in broiler chickens have already been examined extensively by several studies but till now is going quite debate in case of number of birds or floor allowance of birds in per unit area. As, some studies had explored large benefits in reducing stocking density on the performance of broilers (Biligili and Hess, 1995) while others shown that reducing stocking density had

${ }^{+}$To whom correspondence should be addressed : seon@jbnu.ac.kr no influence (Thomas et al., 2004) or even had adverse effects on broiler performances (Feddes et al., 2002). Commercially poultry producers are always tempted to increase number of birds per unit area that are economically beneficial because it minimize the fixed costs of production while maximize the profitability by producing more weight of broiler meat per unit of space (Puron et al., 1995). However, there has been increasing concern over the welfare issues of broilers such as behavioral and physiological stress due to stocked at high densities, especially at later growth period when the body weight per unit area is high. Higher number of birds per $\mathrm{m}^{2}$ which may have reverse effect on environmental condition in the house, can cause of stress and a consequence adversely affect poultry welfare, health and performance (Xie et al., 2014). The negative consequences of high stocking density has been found to lower growth rate, feed intake, utilization of feed efficiency and have adverse effects on bird welfare, in terms of leg weakness, walking ability, and the higher incidence of foot-pad dermatitis and 
hock-burn lesions (Estevez, 2007). Furthermore, with the increase of stocking densities per unit area, quality of litter become decay and enhances temperature and ammonia production in the house which mainly associated due to the fact of high moisture content of the litter and consequently increased incidence of skin lesions and health-related problems (Kestin et al., 1994; Reiter and Bessei, 1998) and air flow rate at the level of bird is reduced, resulting in reduced dissipation of body heat to the air (Ravindran et al., 2006).

Light is an important exogenous environmental factor in broiler production which may have influence on growth rate, welfare, behavioral and production economy. It is well known that lighting factors such as light intensity, duration of light, source of light and spectrum of light could be influenced the physiological and behavioral responses of chickens (Olanrewaju et al., 2006; Sultana et al., 2013). The different colors of light provide various proportion of wavelength whose have varying stimulatory effects on the retina and affects growth and behaviors in chickens (Lewis and Morris, 2000). Most research into the effects of color of light on performance, behavior and well-being of the broilers has been done on monochromatic LED lights and authors are mentioned that using monochromatic LED lights may potentially be beneficial to welfare and performance in broilers as well as much more efficient due to low power consumption and long life as that of conventional light.

However, none of these studies have examined the effects of stocking density in relation between the incandescent and monochromatic LED light sources. Therefore, the aim of the present study was to assess the performance and behavioral traits of broilers reared under different stocking density with incandescent white bulb (IB), LED yellow and white light during the market age of broilers at 35 days.

\section{MATERIALS AND METHODS}

\section{Experimental Treatments and Management}

A total of 1650 one-day-old Ross 308 broiler chicks were purchased from a commercial hatchery, weighed on arrival to obtain information on all average body weight of birds and very close mean body weight of birds were randomly allocated in a $2 \times 3$ factorial arrangement in which consisted with two stocking density (14 birds $/ \mathrm{m}^{2}$ and $22 \mathrm{birds} / \mathrm{m}^{2}$ ) and three light (incandescent white bulb, IB; monochromatic LED yellow and white light) in totaling six treatments. Each treatment was replicated five times and ensured there had no statistically significant differences in initial mean body weight of birds in all the starting pens between the treatments. All birds were fed commercial crumble diet during pre-starter period from day 1 to 7 and pellet diet during starter and grower period from day 8 to 21 and 22 to 35 , respectively. Total dietary metabolic energy for the pre-starter, starter and grower were $3,000,3,100$ and $3,200 \mathrm{kcal} / \mathrm{kg}$ respectively while the values of crude protein were 22.50, 21.50 and $20.50 \%$ respectively. Lighting was provided continuous with an intensity of $25 \pm 2$ lux throughout the experiment and the temperature was maintained in the experimental house at $33^{\circ} \mathrm{C}$ for 1 to 7 days, after which gradually reduced by $3^{\circ} \mathrm{C}$ up to $3^{\text {rd }}$ week of age and thereafter maintained at $22^{\circ} \mathrm{C}$ at the end of the experiment. Chicks were inspected over the experimental period and dead birds were removed following the recording of mortality (pen, date and body weight) to adjust the feed conversion ratio. Birds had offered free access to feed via round plastic feeders and fresh drinking water served via nipple drinker system, feeder and drinker line both were adjustable according to the size of the birds.

\section{Growth Performance}

The total feed intake and body weight of birds were measured by pen basis on 35 days of experiment and average daily feed intake, body weight gain and FCR (feed to gain ratio) were calculated for each treatment. To correct the FCR that was calculated by dividing total feed intake by weight of live plus dead birds on a pen basis.

\section{Observation of Birds Behavior}

The behavior of broilers was assessed in this experiment by set up closed-circuit television (CCTV) camera in two pens of each treatment in the experimental house. The birds involved in sitting, standing, walking and pecking were recorded for 60 minutes since 11:00 am to $12: 00 \mathrm{pm}$ in every observation of period (10 birds were randomly chosen from each replication for each behavior) and individual behavior data averaged. The behavioral patterns have categorized as to 
the following: sitting, without performing other activities; standing, just standing without performing other activities; walking, either walking or running; pecking, either floor, feather or anywhere. In this study, individual behaviors were also grouped into two categories for analysis: active and inactive. The active behaviors were walking and pecking. Sitting and standing activity was considered as inactive behavior.

\section{Statistical Analysis}

All data were subjected to statistical analysis using the GLM procedure of SAS software (SAS 9.1, 2009, SAS Institute Inc., Cary NC) in a completely randomized design. Differences between treatment means were tested using Duncan's multiple range tests and a $P<0.05$ was considered as significant difference.

\section{RESULTS}

\section{Performance Parameters}

As shown in Table 1, performance parameters were statistically differed in interaction between stocking density and light treatment groups. Significantly maximum body weight, weight gain, feed intake and improve feed conversion ratio were observed at density of 14 birds per $\mathrm{m}^{2}$ with monochromatic LED white light group among the treatments. On the other hand, performance parameters of broilers had negatively affected even statistically no consistent difference was found under at 22 birds per $\mathrm{m}^{2}$ with different light treated groups. In this study was observed in case of main effect of light did not attribute bird performances in terms of body weight, weight gain, feed intake and efficiency of feed. For the impact of stocking density of birds per unit area, the

Table 1. Effects of stocking density (14 and $\left.22 \mathrm{birds} / \mathrm{m}^{2}\right)$ and different light system on performance of broiler chickens at 35 days

\begin{tabular}{|c|c|c|c|c|c|}
\hline \multicolumn{2}{|c|}{ Treatments } & \multirow{2}{*}{$\begin{array}{l}\text { Body weight } \\
\text { (g) }\end{array}$} & \multirow{2}{*}{$\begin{array}{l}\text { Weight gain } \\
\text { (g) }\end{array}$} & \multirow{2}{*}{$\begin{array}{c}\text { Feed intake } \\
(\mathrm{g})\end{array}$} & \multirow{2}{*}{ FCR } \\
\hline Density (birds/m²) & Light & & & & \\
\hline \multirow{3}{*}{14} & IB & $2,067.6^{\mathrm{b}}$ & $2,024.0^{b}$ & $3,287.8^{\mathrm{a}}$ & $1.62^{\mathrm{a}}$ \\
\hline & LED Yellow & $2,092.5^{\mathrm{ab}}$ & $2,049.0^{\mathrm{ab}}$ & $3,305.0^{\mathrm{a}}$ & $1.61^{\mathrm{ab}}$ \\
\hline & LED White & $2,119.9^{\mathrm{a}}$ & $2,076.3^{\mathrm{a}}$ & $3,336.0^{\mathrm{a}}$ & $1.60^{\mathrm{b}}$ \\
\hline \multirow{3}{*}{22} & IB & $1,949.7^{\mathrm{c}}$ & $1,907.2^{\mathrm{c}}$ & $3,015.6^{\mathrm{b}}$ & $1.58^{\mathrm{c}}$ \\
\hline & LED Yellow & $1,968.7^{\mathrm{c}}$ & $1,926.0^{\mathrm{c}}$ & $3,051.7^{\mathrm{b}}$ & $1.59^{\mathrm{c}}$ \\
\hline & LED White & $1,977.5^{\mathrm{c}}$ & $1,934.8^{\mathrm{c}}$ & $3,038.7^{\mathrm{b}}$ & $1.57^{\mathrm{c}}$ \\
\hline \multicolumn{6}{|c|}{ - } \\
\hline \multirow{3}{*}{ Light } & IB & $2,008.7$ & $1,965.6$ & $3,151.7$ & 1.60 \\
\hline & LED Yellow & $2,030.6$ & $1,987.5$ & $3,178.3$ & 1.60 \\
\hline & LED White & $2,048.7$ & $2,005.6$ & $3,187.3$ & 1.59 \\
\hline \multirow{2}{*}{ Density } & 14 & $2,093.3^{\mathrm{a}}$ & $2,049.8^{\mathrm{a}}$ & $3,309.6^{\mathrm{a}}$ & $1.61^{\mathrm{a}}$ \\
\hline & 22 & $1,965.3^{\mathrm{b}}$ & $1,922.7^{\mathrm{b}}$ & $3,035.3^{\mathrm{b}}$ & $1.58^{\mathrm{b}}$ \\
\hline SEM & & 14.5 & 14.4 & 29.8 & 0.01 \\
\hline \multicolumn{6}{|l|}{$P$-value } \\
\hline Light $\times$ Density & & $<0.01$ & $<0.01$ & $<0.01$ & $<0.01$ \\
\hline Light & & 0.55 & 0.54 & 0.89 & 0.42 \\
\hline Density & & $<0.01$ & $<0.01$ & $<0.01$ & $<0.01$ \\
\hline
\end{tabular}

${ }^{\mathrm{a} \sim \mathrm{c}}$ values with the same letters in a column are significantly different $(P<0.05)$.

IB, incandescent white bulb; FCR, feed conversion ratio; SEM, standard error of the mean. 
final body weight, weight gain, feed intake and feed conversion were declined significantly by about $6.51 \%, 6.61 \%$, $9.04 \%$ and $1.86 \%$ respectively, due to the fact of density increased from 14 to 22 birds per $\mathrm{m}^{2}$.

\section{Behavioral Observations}

Results of behavior observations are presented in Table 2 . Time spent on standing and walking behavior was significantly differed among the treatments in an interaction between stocking density and different color of illuminations. For the stocking density 14 birds per $\mathrm{m}^{2}$ with various color of illuminations had shown greater spend time on standing and walking, and also total spend time active behavior in walking plus pecking were observed more than that of interaction between high density ( $22 \mathrm{birds} / \mathrm{m}^{2}$ ) with color of illuminations. While, as the main factor of light, time spend on sitting and inactive behavior in sitting plus standing were significantly greater in LED yellow treated group, and walking time was higher in case of IB treated group. In addition, statistically almost same time spend in case of sitting activity was observed in between IB and LED white light group. On the other hand, time spend on walking did not significantly differ in between LED yellow and white light. As the main effect of stocking density in the study, time spend had significantly less in standing, walking as well as active behavior in walking plus pecking for the stocking density increased from 14 to 22 birds per $\mathrm{m}^{2}$.

\section{DISCUSSION}

\section{Body Weight and Weight Gain}

In the present study was found significant effect on growth

Table 2. Effects of stocking density (14 and $22 \mathrm{birds} / \mathrm{m}^{2}$ ) and different light system on behavior of broiler chickens (second per 60 min)

\begin{tabular}{|c|c|c|c|c|c|c|c|}
\hline \multicolumn{2}{|c|}{ Treatments } & \multirow{2}{*}{ Sitting } & \multirow{2}{*}{ Standing } & \multirow{2}{*}{$\begin{array}{l}\text { Inactive } \\
\text { behavior }\end{array}$} & \multirow{2}{*}{ Walking } & \multirow{2}{*}{ Pecking } & \multirow{2}{*}{$\begin{array}{c}\text { Active } \\
\text { behavior }\end{array}$} \\
\hline Density (birds/m²) & Light & & & & & & \\
\hline \multirow{3}{*}{14} & IB & $2,541.6$ & $170.1^{\mathrm{ab}}$ & $2,710.7$ & $149.6^{\mathrm{a}}$ & 82.7 & $232.3^{\mathrm{a}}$ \\
\hline & LED Yellow & $2,686.7$ & $189.0^{\mathrm{ab}}$ & $2,875.8$ & $113.6^{\mathrm{b}}$ & 86.1 & $199.7^{\mathrm{ab}}$ \\
\hline & LED White & $2,543.1$ & $239.6^{\mathrm{a}}$ & $2,782.7$ & $105.4^{\mathrm{b}}$ & 79.3 & $184.7^{\mathrm{bc}}$ \\
\hline \multirow{3}{*}{22} & IB & $2,568.0$ & $104.5^{\mathrm{b}}$ & $2,672.6$ & $81.0^{\mathrm{c}}$ & 66.4 & $147.4^{\mathrm{cd}}$ \\
\hline & LED Yellow & $2,784.0$ & $146.6^{\mathrm{b}}$ & $2,930.2$ & $58.7^{\mathrm{c}}$ & 59.1 & $117.9^{\mathrm{d}}$ \\
\hline & LED White & $2,607.0$ & $134.6^{\mathrm{b}}$ & $2,741.6$ & $62.6^{\mathrm{c}}$ & 72.9 & $135.4^{\mathrm{d}}$ \\
\hline & ----- & - & ---- Main & - & ---------- & & \\
\hline \multirow{3}{*}{ Light } & IB & $2,554.3^{\mathrm{b}}$ & 137.4 & $2,691.6^{\mathrm{b}}$ & $115.3^{\mathrm{a}}$ & 74.6 & 189.9 \\
\hline & LED Yellow & $2,735.4^{\mathrm{a}}$ & 167.8 & $2,903.1^{\mathrm{a}}$ & $86.1^{\mathrm{b}}$ & 72.6 & 158.8 \\
\hline & LED White & $2,575.1^{\mathrm{b}}$ & 187.1 & $2,762.1^{b}$ & $84.0^{\mathrm{b}}$ & 76.1 & 160.1 \\
\hline \multirow{2}{*}{ Density } & 14 & $2,590.1$ & $199.6^{\mathrm{a}}$ & $2,789.7$ & $122.9^{\mathrm{a}}$ & 82.7 & $205.6^{\mathrm{a}}$ \\
\hline & 22 & $2,653.0$ & $128.5^{\mathrm{b}}$ & $2,781.6$ & $67.4^{\mathrm{b}}$ & 66.1 & $133.6^{\mathrm{b}}$ \\
\hline SEM & & 33.1 & 12.4 & 29.3 & 5.7 & 5.3 & 8.6 \\
\hline \multicolumn{8}{|l|}{$P$-value } \\
\hline Light $\times$ Density & & 0.21 & 0.02 & 0.08 & $<0.01$ & 0.69 & $<0.01$ \\
\hline Light & & 0.05 & 0.26 & 0.01 & 0.04 & 0.97 & 0.25 \\
\hline Density & & 0.35 & $<0.01$ & 0.89 & $<0.01$ & 0.12 & $<0.01$ \\
\hline
\end{tabular}

${ }^{\mathrm{a} \sim \mathrm{c}}$ values with the same letters in a column are significantly different $(P<0.05)$.

IB, incandescent white bulb; SEM, standard error of the mean. 
performance of broilers in interaction between stocking density and light treatment groups over the entire experimental period. On an overall, statistically increase final body weight, weight gain, feed intake and improve feed to gain ratio of broilers were observed under LED white light and 14 birds per $\mathrm{m}^{2}$ treatment group. This difference could probably be attributed for the positive effect of adequate floor space per unit area as the age of birds with LED light, in addition, seems to LED light which may have provide low proportion of wavelength than incandescent light resulting that birds could be felt quite clam and utilized feed in the body more thereby led to influence the growth of broilers. The results of the present study are in keeping with those reported by Mosa et al. (2014) who observed that stocking density at 12 birds per $\mathrm{m}^{2}$ with light colors had stimulatory impact on breast muscle and dressing yield over the period at 35 days as compared that of 15 and 18 birds per $\mathrm{m}^{2}$ with light treated groups. As the effect of stocking density, Uzum and Toplu (2013) reported that weight gain of broilers was less with increased stocking density from 12 to 18 birds per $\mathrm{m}^{2}$ which is concomitant with our current study. It has been reported that high stocking density which is the cause of poor air quality for an inadequate exchange of air, increased ammonia production and reduced access to feed and water resulting in reduced growth rate and feed efficiency of broilers (Feddes et al., 2002; Dozier et al., 2006). Similar observations were also reported by Bilgili and Hess (1995) and Dozier et al. (2005) those who concluded that significantly depressed growth of birds and increased stress level for the higher stocking density of birds in per unit area. However, the difference in growth rate of broilers in the present study could be associated for the progressive decline in feed and nutrients intake probably due to insufficient space to access in feeders for higher stocking density with increasing age of birds or it may also be related to decline the efficiency of nutrients utilization by the stress associated with overcrowding of birds.

For the sole effect of light spectrum was not affected the birds performances which was observed in this study. The results of current study however was consistent with the findings of Senaratna et al. (2008) and Prayitno et al. (1997) those who found no stimulatory effects of varying light color treatments (blue, green, red and white) on body weight, feed consumption and feed utilization efficiency of broilers. On the other hand, a number of experiments have shown that effect of light color on broiler performance is still inconsistent. As, Rozenboim et al. (2004) showed that broilers reared under monochromatic blue or green light stimulate growth at 35 days of age through enhancing the proliferation of muscle cells than those exposed to red or white light. Another study, Ke et al. (2011) also observed body weight had significantly heavier when broilers were reared under blue light than under green, red and white light. Hassan et al. (2014) opined that accelerate growth of broilers for the effect of blue color light which could probably be stimulated by secretion of testosterone hormone.

\section{Feed Intake and Feed Conversion Ratio}

As the main factors different colors of light impact on feed intake in the current study, there was no difference observed. Whereas, significantly decline feed intake was found for the sake of high stocking density per unit floor surface as that of normal density. Similar to the current study, it has been reported that feed intake was declined due to increased stocking density which may be generally occurred due to less ability to express normal postural adjustments or restricted access to the feeders with increasing body weight of birds as the age (Abudabos et al., 2013). Dozier et al. (2005) reported an insufficient feeding space for high density over the period from 1 to 49 days of age, in which made hindrance in case of general feed consumption of birds. Likewise, another study opined that feed intake of broilers was linearly decreased with the increasing stocking density at $28,34,39 \mathrm{~kg} \mathrm{~m}^{-2}$, who claimed that it had to be inhibited access to feeder space by increasing stocking density with age of birds (Mclean et al., 2002). In the present study, the FCR was improved in case of stocking density increased from 14 to 22 birds per $\mathrm{m}^{2}$, it may probably be associated due to be insufficient feeding space per unit area with increasing the body weight of birds as the age which resulting that led to decrease in total feed consumption and accompanied with decrease in live weight gain. The finding of feed to gain ratio was coin- 
cided with recent previous results of Abudabos et al. (2013) reported that reduction of FCR was associated with higher stocking density and led to reduce feed consumption, it indicate that physical access to feeders was possibly to be limited due to insufficient feeding space in higher stocking density group and consequently growth performance of broilers was suppressed. In addition, the consistent trend of stocking density on feed conversation ratio was not found in several earlier studies. As, some studies have shown that feed conversion ratio had improved for number of birds increase in per unit area, they also expressed that it could be associated for lower feed consumption due to competition of access to feeders (Tsiouris et al., 2015). Whereas some researcher also found that feed conversion ratio had increased because total amount of feed consumption was more by increasing stocking density of birds per unit area than that of lower density (Ravindran et al., 2006; Skomorucha et al., 2009) while other authors have shown that stocking density had not influenced the efficiency of feed utilization (Thomas et al., 2004; Sekeroglu et al., 2011).

\section{Behavioral Observations}

In the current study, less walking and standing ability were observed for the high density when raised at 22 birds per $\mathrm{m}^{2}$, indicate that birds may be felt discomfort for the limited space per bird because of growth rate was increased with age of birds, even may have to due to incidence of leg weakness and foot pad dermatitis and hock burn lesions. In other sense, impair environmental condition in the house due to the effect of high stocking density may have to an increase moisture content and ammonia gas in litter material and negatively can lead to welfare of birds. Earlier studies by some researchers have shown that welfare of birds had negatively to be reflected by physical restriction of movement due to limited space per of bird (Estevez, 2007). Similarly in the present study, we noticed that locomotive activity such walking ability was declined due to density of birds increased from 14 to 22 numbers per unit area which was concomitant with the results of Kestin et al. (1994). In addition, Thomas et al. (2004) who studied the effect of different stocking density at $5,10,15$ and 20 birds per $\mathrm{m}^{2}$ and observed that welfare of birds was adversely affected as increasing the number of birds per unit area $\left(\mathrm{m}^{2}\right)$, however, the authors have been suggested that hock and food pad burns make a significant negative impact to the overall prevalence of poor walking ability when birds reared under higher densities. In another study, Sorensen et al. (2000) reported that less time spent on walking which may be the cause of the greater incidence of leg weakness and constraint movement ability when birds housed at higher densities especially at the later age period, which was in accordance with the current study.

In this study, birds were more inactive under the yellow light treatment which exposed by spend more time in sitting. However, it may have been due to yellow light where birds were feel greater calm and relaxed than birds exposed to other lighting color. On the other hand, birds reared under IB light were more active as expressed by walking than those of LED yellow and white light. The increase in activity of birds under IB light, in this regard it may possible reason that incandescent light contain high proportion of wavelength light which may be passed into the retina, skull, and skin more efficiently than that of LED light treatment (Hartwig and Veen, 1979). About the using light source in poultry industry, earlier some studies have demonstrated that light of different color wavelength has varying stimulatory on the retina and can result in behavioral changes that affect tissue growth and development (Prayitno et al., 1997; Sultana et al., 2013).

\section{CONCLUSION}

The present study indicated that performance traits in terms of body weight, weight gain and feed conversion were improved at 35 days in broilers exposed to LED light with 14 birds per $\mathrm{m}^{2}$ groups among the treatments while in the case of birds behavior, higher time spent on standing, walking and active behavior in walking plus pecking was appeared for the 14 birds per $\mathrm{m}^{2}$ with light treated groups. The main effects of stocking density at 22 birds per $\mathrm{m}^{2}$ negatively affected economically important traits and time spend for standing, walking, and walking plus pecking behavior were decreased, means that birds may be felt uneasiness due to limited space with increasing age of birds and 
thereby stress level or other health-related problems might be associated. The inactive behavior appeared to be enhanced by LED yellow and walking activity increased under IB light for the effect of lights. Thus, it can be concluded that stocking density $14 \mathrm{birds} / \mathrm{m}^{2}$ or with LED light making the environment more compatible for performance and welfare of birds. Meanwhile, further follow up studies have to be required to more clarify whether and how stocking density in relation with light influence performance and behavioral traits of broilers.

\section{ACKNOWLEDGMENTS}

This work was supported by Korea Institute of Planning and Evaluation for Technology in Food, Agriculture, Forestry (IPET) through Agriculture, Food and Rural Affairs Research Center Support Program, funded by Ministry of Agriculture, Food and Rural Affairs (MAFRA; 716002-7).

\section{ORCID}

Chun Ik Lim https://orcid.org/0000-0003-0386-5694

Md Masud Rana https://orcid.org/0000-0003-1410-054X

Il Bok Choi

https://orcid.org/0000-0001-5325-0589

Kyeong Seon Ryu https://orcid.org/0000-0002-3246-8412

\section{REFERENCES}

Abudabos AM, Samara EM, Hussein EOS, Al-Ghadi MQ, Al-Atiyat RM 2013 Imapct of stocking density on the performance and welfare of broiler chickens. Ital J Anim Sci 12(1):e11.

Biligili SF, Hess JB 1995 Placement density influences broiler carcass grade and meat yields. J Appl Poult Res 4(4): 384-389.

Dozier III WA, Thaxton JP, Branton SL, Morgan GM, Miles DM, Roush DB, Lott BD, Vizzier-Thaxton Y 2005 Stocking density effects on growth performance and processing yields of heavy broilers. Poult Sci 84(8):1332-1338.

Dozier III WA, Thaxton JP, Purswell JL, Olanrewaju HA, Branton SL, Roush WB 2006 Stocking density effects on male broilers grown to 1.8 kilograms of body weight. Poult Sci 85(2):344-351.

Estevez I 2007 Density allowances for broilers: where to set the limits? Poult Sci 86(6):1265-1272.

Feddes JJR, Emmanuel EJ, Zuidhoft MJ 2002 Broiler performance, body weight variance, feed and water intake, and carcass quality at different stocking densities. Poult Sci 81(6):774-779.

Hartwig HG, Veen T 1979 Spectral characteristics of visible radiation penetrating into the brain and stimulating extraretinal photoreceptors. J Comp Physiol A 130(3):277-282.

Hassan MR, Sultana S, Choe HS, Ryu KS 2014 A comparison of monochromatic and mixed LED light color on performance, bone mineral density, meat and blood properties and immunity of broiler chicks. Poult Sci 51(2): 195-201

Ke YY, Liu WJ, Wang ZX, Chen YX 2011 Effect of monochromatic light on quality properties and antioxidation of meat in broilers. Poult Sci 90(11):2632-2637.

Kestin SC, Knowles TG, Tinch AE, Gregory NG 1994 Prevalence of leg weakness in broilers and its relationship with genotype. Veterinary Record 131(9):190-194.

Lewis PD, Morris TR 2000 Poultry and colored light. World Poult Sci J 56(3):189-207.

Mclean JA, Savory J, Sparks N 2002 Welfare of male and female broiler chickens in relation to stocking density, as indicated by performance, health and behavior. Anim Welf 11(1):55-73.

Mosa RK, Abbas RJ, Abu Tabeekh MAS 2014 The effect of color light and stocking desnity on some traits of broiler carcasses. MRVSA 3(2):24-35.

Olanrewaju HA, Thaxton JP, Dozier III WA, Purswell J, Roush WB, Branton SL 2006 A review of lighting program for broiler production. Int J Poult Sci 5(4):301-308.

Prayitno DS, Philips CJC, Stokes DK 1997 The effects of color and intensity of light on behavior and leg disorder in broiler chikens. Poult Sci 76(12):1674-1681.

Puron D, Santamaria R, Segura JC, Alamilla JL 1995 Broiler performance at different stocking densities. J Appl Poult Res 4(1):55-60.

Ravindran V, Thomas DV, Thomas DG, Morel PCH 2006 
Performance and welfare of broilers as affected by stocking density and zinc bacitracin supplementation. Anim Sci J 77(1):110-116.

Reiter K, Bessei W 1998 Possibilities to reduce leg disorders in broilers and turkeys (review). Europ Poult Sci 62(4): 145-149.

Rozenboim I, Biran I, Chaiseha Y, Yahav S, Rosenstrauch A, Sklan D, Halevy O 2004 The effect of a green and blue monochromatic light combination on broiler growth and development. Pout Sci 83(5):842-845.

Sekeroglu A, Sarica M, Gulay MS, Duman M 2011 Effect of stocking density on chick performance, internal organ weights and blood parameters in broilers. J Anim Vet Adv 10(2):246-250.

Senaratna D, Samarakone T 2008 Effect of the color of light on growth performance, behavior and bone parameters of broiler chickens. Tropical Agricultural Research 20(1):185192.

Skomorucha I, Muchacka R, Sosnowkacazajka E, Herbul E 2009 Response of broiler chickens from three genetic groups to different stocking densities. Ann Anim Sci 9(2):175-184.

Sorensen P, Su G, Kestin SC 2000 Effects of age and stocking density on leg weakness in broiler chickens. Poult Sci 79(6):864-870.
Sultana S, Hassan MR, Choe HS, Ryu KS 2013 The effect of monochromatic and mixed LED light color on the behavior and fear responses of broiler chicken. Avian Biol Res 6(3):207-2014.

Thomas DG, Ravindran V, Thomas DV, Camden BJ, Cottam YH, Morel PCH, Cook CJ 2004 Influence of stocking density on the performance, carcass characteristics and selected welfare indicators of broiler chickens. New Zeal Vet J 52(2):76-81.

Tsiouris V, Georgopoulou I, Batzios C, Pappaioannou N, Ducatelle R, Fortomaris P 2015 High stocking density as a predisposing factor for necrotic enteritis in broiler chicks. Avian Pathol 44(2):59-66.

Uzum MH, Toplu HD 2013 Effect of stocking density and feed restriction on performance, carcass, meat quality characteristics and some stress parameters in broilers under heat stress. Revue Med Vet 164(12):546-554.

Xie M, Jiang Y, Tang J, Wen ZG, Huang W, Hou SS 2014 Effects of stocking density on growth performance, carcass traits, and foot pad lesions of white pekin ducks. Poult Sci 93(7):1644-1648.

Received Nov. 24, 2019, Revised Dec. 22, 2019, Accepted Dec. 22, 2019 